\title{
Primary renal angiosarcoma
}

\author{
Eric Gourley, ${ }^{1}$ Gilda Digman, ${ }^{2}$ Marlo Nicolas, ${ }^{3}$ Dharam Kaushik ${ }^{4}$
}

${ }^{1}$ Urology, University of Texas Health, San Antonio, San Antonio, TX, USA ${ }^{2}$ Urology, University of Texas Health, San Antonio, San Antonio, Texas, USA ${ }^{3}$ Pathology, University of Texas Health Science Center at San Antonio, San Antonio, Texas, USA

${ }^{4}$ Urology, University of Texas Health, San Antonio, San Antonio, Texas, USA

\section{Correspondence to} Dr Dharam Kaushik, kaushik@uthscsa.edu

Accepted 9 July 2018

Check for updates

(c) BMJ Publishing Group Limited 2018. No commercial re-use. See rights and permissions. Published by BMJ.

\begin{tabular}{|l|}
\hline To cite: Gourley E, \\
Digman G, Nicolas M, et al. \\
BMJ Case Rep Published \\
Online First: [please \\
include Day Month Year]. \\
doi:10.1136/bcr-2017- \\
222672 \\
\hline
\end{tabular}

\section{SUMMARY}

An older male patient with a history of tachycardia treated with atenolol presented to an outside hospital on 22 February 2017 with acute right flank pain. He had a CT scan which revealed a large right renal mass with acute haemorrhage. He was initially managed with interventional radiology guided embolism on 25 February 2017 due to the ongoing bleeding and haemodynamic instability. He was then transferred to our institution. He underwent right radical nephrectomy on 13 March 2017. His pathology revealed a $12.5 \times 6 \times 4.5 \mathrm{~cm}$ mass consistent with angiosarcoma of the right kidney with negative margins. Final pathology was pT2b with extension of the mass into the renal vein and perirenal adipose tissue. He was discharged soon after surgery. He was recommended to undergo adjuvant chemotherapy.

\section{BACKGROUND}

Primary renal angiosarcomas are very rare tumours with very few reported in the literature. There is paucity of data on management of these tumours. There have been approximately 40 cases reported in the literature. This is a unique case of renal angiosarcoma as his initial presentation was right flank pain.

\section{CASE PRESENTATION}

An older male patient with a history of tachycardia of unknown origin. He did not have any significant social or family history. He had no history of tobacco or alcohol use. He presented to a community hospital with acute onset right flank pain. Further evaluation by CT scan showed a large greater than $10 \mathrm{~cm}$ heterogenous mass. Further imaging did not show any obvious metastatic disease. He continued to be haemodynamically unstable, requiring transfusions. Subsequently, he underwent IR embolisation of the kidney 3 days after initial presentation. He developed a right upper extremity deep vein thrombosis, pneumonia and an ileus after the embolisation. He was eventually transferred to our facility for further management.

\section{INVESTIGATIONS}

Further imaging was obtained on arrival that showed a heterogenous appearing right kidney with hyperdense areas in the upper pole, likely representing embolised tumour and also area with high-density fluid surrounding the kidney and in the retroperitoneum representing haematoma. There was no evidence of metastatic disease in the chest, abdomen or pelvis (figure 1).

\section{DIFFERENTIAL DIAGNOSIS}

The differential diagnoses were retroperitoneal haematoma, renal cell carcinoma with spontaneous bleed, angiomyolipoma (AML) or other more rare renal lesions including angiosarcoma or secondary carcinoma. Secondary malignancies can be typically ruled out with the prior imaging performed.

\section{TREATMENT}

Nineteen days after the initial presentation, he underwent a right radical nephrectomy with resection of retroperitoneal tissue.

After consent and correct identification of side, the patient was taken to the operating room and placed in supine position. A right subcostal incision was made, and the peritoneum was accessed. Immediately was seen a very large perinephric haematoma which had distorted the right retroperitoneum. There was significant tissue reaction encompassing the inferior vena cava (IVC) and the liver, and these were pushed medially because of the significant perinephric haematoma. Because of the extensive adhesions and to obtain adequate control of bleeding, the incision was extended to the left side. There were extremely dense adhesions between the kidney and IVC and duodenum which required tedious dissection. Frozen sections from the soft tissues around the kidney were sent, and it was noted to be poorly differentiated sarcomatoid changes consistent with a very aggressive sarcoma or sarcomatoid differentiation of renal cell. There was extension of the soft tissue in the retrocaval plane and towards the liver. The mass and kidney were successfully removed. The final frozen sections from the soft tissues around the IVC and around the liver were negative.

He tolerated the surgery well and was discharged on postoperative day 4 in stable condition. He was followed up in clinic and was doing well 2 weeks after discharge.

\section{OUTCOME AND FOLLOW-UP}

Pathology showed a right kidney with angiosarcoma measuring $12.5 \mathrm{~cm}$ in maximum dimension with angiosarcoma involving the renal vein and perirenal adipose tissue extending to the hilar soft tissue margin with negative margins. All surgical margins were negative on final pathology. The tumour was positive for erythroblast transformation-specific related Gene (ERG)and cluster of differentiation 31 (CD31) and negative for cytokeratin $\mathrm{AE}$ (Anion Exchanger)1/AE3, supporting the diagnosis of angiosarcoma. This angiosarcoma is high grade (poorly differentiated angiosarcoma: score 3 of 3 ; mitosis count: score of 3 of 3 ; tumour necrosis: 


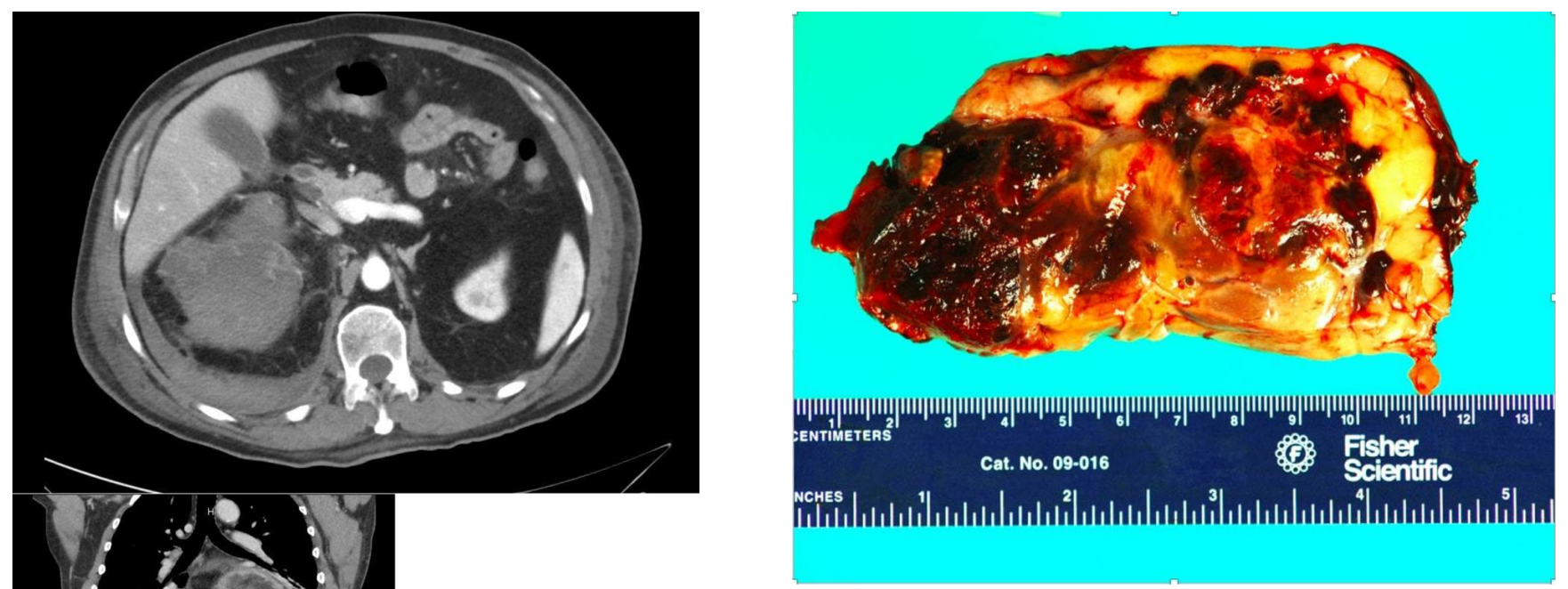

Figure 2 Gross pathology of right kidney and mass.

local medical oncologist closer to his home. He refused chemotherapy and died few weeks later.

\section{DISCUSSION}

Angiosarcoma is a high-grade and aggressive tumour that accounts for $2 \%$ of soft tissue sarcomas with majority arising from skin and soft tissues with a very small minority arising originally from the kidney. ${ }^{12}$ There have been roughly 40 cases documented in the literature. ${ }^{3}$ These occur more commonly in white males between the age of 60 and 70 years. ${ }^{3}$ These tumours originate from the endothelium of the blood and lymphatic vessels and can arise anywhere in the body. ${ }^{4}$ They have the potential to metastasise most commonly to the liver, lungs and bones. This case represents a rare presentation of renal angiosarcoma in a patient with presenting sign of right flank pain due to the acute bleed. There is paucity of data on chemotherapeutic approach for primary renal angiosarcomas and recommendations are based on extrapolation of chemotherapy data from other angiosarcomas. ${ }^{3}$ Based on these, the usual treatment is an isofamidebased regimen either with cisplatin or doxorubicin. These have response rate of $44 \%$ and $71 \%$, respectively. ${ }^{24}$ Prognostic factors for these tumours include tumour size and presence of metastases

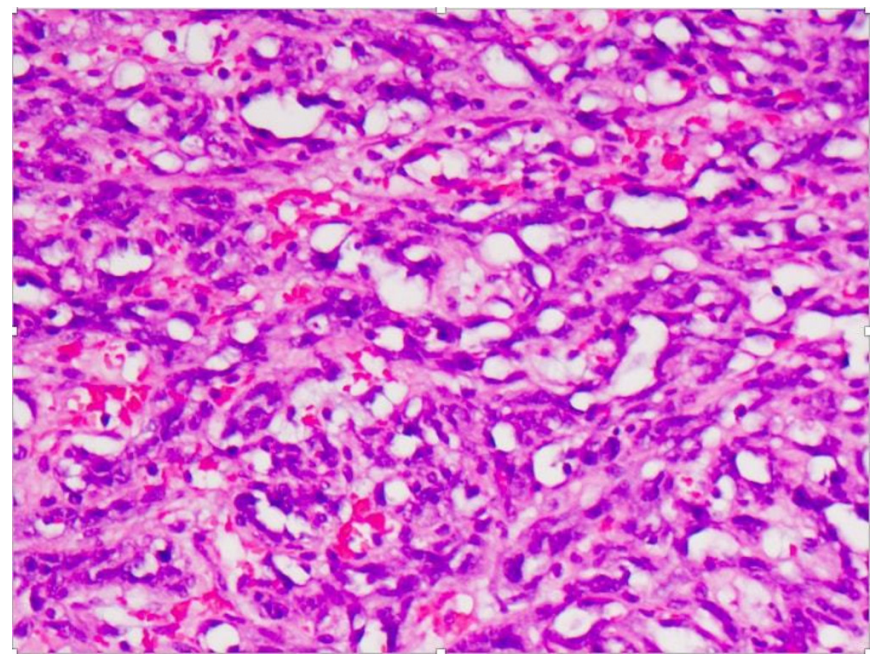

Figure 3 The tumour is composed of pleomorphic spindle cells with vasoformative growth pattern.

score of 1 of 2 ; total score of 7 of 8 that makes it a grade 3 of 3 sarcoma). This is a stage pT2b (based on the seventh American Joint Committee on Cancer (AJCC staging system). (figures 2 and 3).

He was discussed at a multidisciplinary genitourinary tumour board, and it was recommended that he undergo aggressive chemotherapy. At the patient's request, he was referred back to a 
at the time of diagnosis. The 5 -year survival for tumours $>5 \mathrm{~cm}$ is $13 \%$ and only $32 \%$ for tumours less than $5 \mathrm{~cm} .^{3}$ There is frequently local recurrence for angiosarcomas. The treatment of localised disease includes wide resection followed by adjuvant chemotherapy. ${ }^{3}$ Currently, radiation therapy is controversial in the treatment of these malignancies. ${ }^{3}$

\section{Learning points}

- Angiosarcomas are an extremely aggressive tumour. Early surgical resection followed by adjuvant chemotherapy may provide patients with symptomatic control.

- Presenting signs for these are often flank pain, haematuria and palpable flank mass.

- Primary treatment for localised angiosarcoma is wide local excision followed typically by systemic chemotherapy.

- These tumours are difficult to diagnose on imaging alone and the best way to diagnose is by pathology after surgical removal.
Contributors EG and GD provided the initial research into the background and purpose of the case report. EG and GD co-wrote the manuscript including background, investigation, presentation and discussion. MN provided intellectual input with regard to the Pathology portion of the manuscript and provided further editing recommendations. DK provided intellectual input into the background, investigation, treatment, surgical expertise and overall organisation of the paper. DK provided ongoing guidance and final editing of the manuscript.

Funding The authors have not declared a specific grant for this research from any funding agency in the public, commercial or not-for-profit sectors.

Competing interests None declared.

Patient consent Not required.

Provenance and peer review Not commissioned; externally peer reviewed.

\section{REFERENCES}

1 Leggio L, Addolorato G, Abenavoli L, et al. Primary renal angiosarcoma: a rare malignancy. A case report and review of the literature. Urol Oncol 2006;24:307-12

2 Carnero López B, Fernández Pérez I, Carrasco Alvarez JA, et al. Renal primary angiosarcoma. Clin Trans/ Oncol 2007;9:806-10.

3 Zhang HM, Yan Y, Luo M, et al. Primary angiosarcoma of the kidney: case analysis and literature review. Int J Clin Exp Pathol 2014;7:3555-62.

4 Papadimitriou VD, Stamatiou KN, Takos DM, et al. Angiosarcoma of kidney: a case report and review of literature. Urol J 2009;6:223-5.

Copyright 2018 BMJ Publishing Group. All rights reserved. For permission to reuse any of this content visit

http://group.bmj.com/group/rights-licensing/permissions.

BMJ Case Report Fellows may re-use this article for personal use and teaching without any further permission.

Become a Fellow of BMJ Case Reports today and you can:

- Submit as many cases as you like

- Enjoy fast sympathetic peer review and rapid publication of accepted articles

- Access all the published articles

Re-use any of the published material for personal use and teaching without further permission

For information on Institutional Fellowships contact consortiasales@bmjgroup.com

Visit casereports.bmj.com for more articles like this and to become a Fellow 